\title{
Assessment of Probiotics Mixture on Memory Function, Inflammation Markers, and Oxidative Stress in an Alzheimer's Disease Model of Rats
}

\author{
Shima Mehrabadi ${ }^{1}$ and Seyed Shahabeddin Sadr ${ }^{1,2^{*}}$ \\ ${ }^{1}$ Department of Physiology, School of Medicine, Tehran University of Medical Sciences, Tehran, Iran; \\ ${ }^{2}$ Electrophysiology Research Center, Neuroscience Institute, Tehran University of Medical Sciences, Tehran, Iran
}

Received 20 October 2019; accepted 11 January 2020; published online 29 February 2020

\begin{abstract}
Background: The most important cause of neurodegeneration in $A D$ is associated with inflammation and oxidative stress. Probiotics are microorganisms that are believed to be beneficial to human and animals. Probiotics reduce oxidative stress and inflammation in some cases. Therefore, this study determined the effects of probiotics mixture on the biomarkers of oxidative stress and inflammation in an AD model of rats. Methods: In this study, 50 rats were allocated to five groups, namely control, sham, and $A D$ groups with $A B 1-40$ intra-hippocampal injection, as well as $A D+$ rivastigmine and $A D+$ probiotics groups with $A B 1-40$ intra-hippocampal injection and $2 \mathrm{ml}\left(10^{10}\right.$ CFU) of probiotics (Lactobacillus reuteri, Lactobacillus rhamnosus, and Bifidobacterium infantis) orally once a day for 10 weeks. MWM was used to assess memory and learning. To detect $A \beta$ plaque, Congo red staining was used. Oxidative stress was monitored by measuring the MDA level and SOD activity, and to assess inflammation markers (IL-1 $\beta$ and TNF- $\alpha$ ) in the hippocampus, ELISA method was employed. Results: Spatial memory improved significantly in treatment group as measured by MWM. Probiotics administration reduced A $\beta$ plaques in AD rats. MDA decreased and SOD increased in the treatment group. Besides, probiotics reduced IL-1 $\beta$ and TNF- $\alpha$ as inflammation markers in the AD model of rats. Conclusion: Our data revealed that probiotics are helpful in attenuating inflammation and oxidative stress in AD. DOI: 10.29252/ibj.24.4.220
\end{abstract}

Keywords: Alzheimer's disease, Inflammation, Probiotics, Oxidative stress

Corresponding Author: Seyed Shahabeddin Sadr

Electrophysiology Research Center, Neuroscience Institute, Tehran University of Medical Sciences, Tehran, Iran; Tel.: (+98-21) 61192474;

Fax: (+98-21) 66938885; E-mail: shahabsadr2012@yahoo.com

\section{INTRODUCTION}

A lzheimer's disease is a progressive, neurodegenerative disease most often characterized by initial cognitive decline and appearance of $\mathrm{A} \beta$ plaques in brain. Although the cause of $\mathrm{AD}$ is not known, activated microglia and released proinflammatory cytokines have the most important role of neuroinflammation and neurodegeneration in $\mathrm{AD}^{[1-4]}$. In addition, chronic oxidative stress in $\mathrm{AD}$ brains provokes inflammation through the nuclear factor-kappa B signaling pathway, which in turn, accelerates the aging process ${ }^{[5,6]}$.

The gut microbiota is defined as the largest reservoir of microbes (about $10^{14}$ ) in the human body ${ }^{[7]}$. Studies have shown that there is a bidirectional communication between gut and other organs ${ }^{[8,9]}$. Disturbances in this cross talks could result in certain diseases like irritable bowel syndrome, inflammatory bowel disease, depression, anxiety, and neurodevelopmental disorders such as autism and Parkinson's disease, as well as other neurodegenerative and neuroinflammatory disorders like $\mathrm{AD}^{[10-12]}$. A recent study has suggested that gut microbiota alters in $\mathrm{AD}$ patients and may

\section{Abbreviations:}

$\mathbf{A} \boldsymbol{\beta}, \boldsymbol{\beta}$-amyloid; AD, Alzheimer's disease; CNS, central nervous system; GIT, gastrointestinal tract; $\mathbf{M D A}$, malondialdehyde; $\mathbf{M S}$, multiple sclerosis; MWM, Morris water maze; SOD, superoxide dismutase 
involve in the pathogenesis of $\mathrm{AD}^{[13]}$. In fact, the specific role of gut microbiota is to modulate neuroimmune functions, which indicates that GIT may significantly influence the process of neurodegeneration, especially in association with $\mathrm{AD}^{[14-17]}$. It has also been reported that gut microbiota is a key player in regulating the innate and adaptive immune response and could affect inflammation responses ${ }^{[8,9]}$.

Probiotics are live microbial food supplements with certain benefits for consumers and are thought to maintain or improve the intestinal microbial balance $^{[18]}$. Probiotics have been displayed to improve brain-gut-microbiota axis ${ }^{[19,20]}$ and regulate nervous system through neuroendocrine, neurometabolic and neuroimmunologic mechanisms ${ }^{[21,22]}$. They can also reduce some oxidative stress biomarkers and inflammatory cytokines ${ }^{[23]}$.

There are few studies on the effect of probiotics on AD and neuroinflammation associated with this disease; however, the underlying mechanism remains still unclear. To this end, this study was undertaken to investigate the impact of probiotics Lactobacillus reuteri, Lactobacillus rhamnosus, and Bifidobacterium infantis on memory function, neuroinflammation, and oxidative stress in an AD model of rats.

\section{MATERIALS AND METHODS}

\section{Animals}

Fifty male Wistar rats (200-250 g) were used in this study. Each animal was housed in one cage and had free access to food and water ${ }^{[24]}$. Rats were randomly divided into five groups ( $\mathrm{n}=10$ per group): (1) control group, without any intervention and injection; (2) sham group, with PBS intrahippocampal injection without any dietary plan; (3) Alzheimer group, with A $\beta 1-40$ intrahippocampal injection without any dietary plan; (4) Alzheimer-probiotics $(\mathrm{A}+\mathrm{P})$ group, with $\mathrm{A} \beta 1-40$ intrahippocampal injection and receiving $2 \mathrm{~g}\left(10^{10}\right.$ CFU) probiotics (Lactobacillus reuteri, Lactobacillus rhamnosus, and Bifidobacterium infantis) orally once a day for 10 weeks; (5) $\mathrm{AD}+$ rivastigmine group, receiving rivastigmine $(0.6 \mathrm{mg} / \mathrm{kg})$ orally once a day for two weeks. The dietary plan started five weeks before injecting $A \beta 1-40$ and continued for five weeks after injection. Following behavioral studies, rats were anesthetized with the intraperitoneal injection of ketamine $(90 \mathrm{mg} / \mathrm{kg})$ and xylazine $(5 \mathrm{mg} / \mathrm{kg})$ to extract brain, which was then stored in $-70{ }^{\circ} \mathrm{C}$ for ELISA studies and oxidative stress measurement.

\section{Alzheimer's model preparation \\ In the first step, to make oligomer $A \beta 1-40$ peptides,}

$1 \mathrm{mg}$ of $\mathrm{A} \beta$ dissolved in $200 \mu \mathrm{l}$ of PBS was incubated at $37{ }^{\circ} \mathrm{C}$ for one week. Then the atomic force microscopy was used to approve oligomer formation (Fig. 1). To induce $\mathrm{AD}$, rats were anesthetized with ketamine $(70 \mathrm{mg} / \mathrm{kg})+$ xylazine $(10 \mathrm{mg} / \mathrm{kg})$ and then placed in a stereotaxic device. After shaving and puncturing the skull, $2 \mu \mathrm{l}$ of $\mathrm{A} \beta 1-40$ solution was injected into right dorsal hippocampus (CA-1 region) using a Hamilton syringe according to Paxinos and Watson atlas $(\mathrm{AP}=-4.2, \mathrm{ML}=3, \mathrm{DV}=3.5)^{[25]}$. Fourteen days after recovery, animals entered the study.

\section{Probiotics preparation}

Probiotics drop containing Lactobacillus reuteri, Lactobacillus rhamnosus, and Bifidobacterium infantis was obtained from Mahya Darou Company (Tehran, Iran). The probiotics drop $(2 \mathrm{ml})$ was dissolved in 30 $\mathrm{ml}$ of tap water; the solution contained $10^{10} \mathrm{CFU}$ probiotics. Water consumption was monitored. In the treatment group, probiotics consumption continued daily for 10 weeks.

\section{Behavioral study}

MWM was used to assess the spatial memory of rats after 10 weeks of $A \beta$ injection. A pool with black color and the diameter of $140 \mathrm{~cm}$ and depth of $35 \mathrm{~cm}$ was used in this study and filled with water (25 \pm $2{ }^{\circ} \mathrm{C}$ ). The pool had four quadrants, one of which was target quadrant with a plexiglass platform placed in it. The platform was invisible and placed $1 \mathrm{~cm}$ under water. Rats were trained for four days, and probe test was conducted in one day. Each training day contained four trials that took $60 \mathrm{~s}$. In each trial, rats should find the platform and if they fail to do so, they were placed on the platform to learn its place. Animals were allowed to rest for $15 \mathrm{~s}$, and then the next trial started.

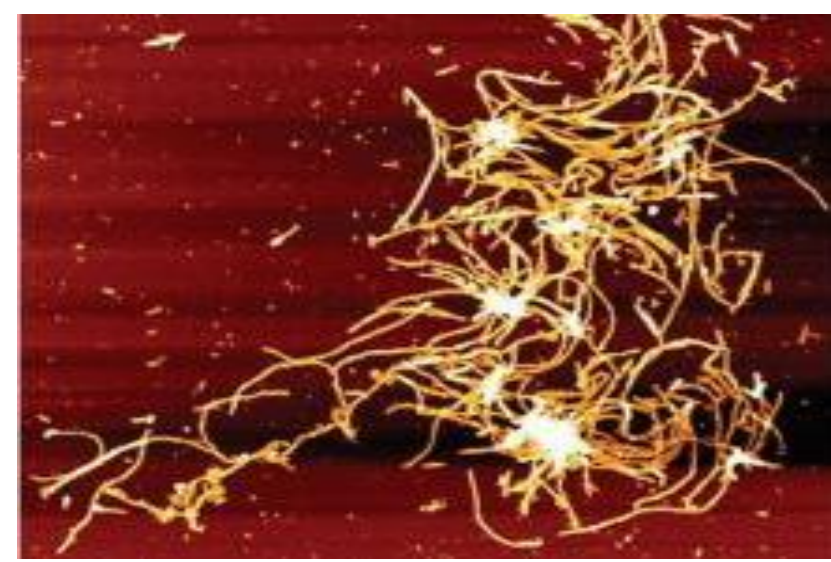

Fig. 1. Atomic force microscopy of A $A 1-40$ peptides after being dissolved in PBS and incubated for one week. The Figure shows many fibril clusters from A $\beta 1-40$ peptides aggregation. Scan size $=500 \times 500 \mathrm{~nm}$. 
Finally, in probe test ( $5^{\text {th }}$ day of the test), the platform was removed from pool, and rats were released randomly to one quadrant and they were allowed to swim for 60 days. The time of rats presence in the target quadrant was calculated ${ }^{[26]}$. All steps were recorded with a camera above the center of the pool, and the time elapsed, velocity, and the time spent in the target quadrant in the probe test were calculated using Radyab software ${ }^{[4]}$.

\section{A $\beta$ plaques detection}

To detect $A \beta$ plaques, two rats were chosen randomly, their brains were extracted and kept in $15 \%$ formalin for $72 \mathrm{~h}$. Paraffin-sliced sections with $5 \mu \mathrm{m}$ thick were prepared and stained by Congo red to view amyloid plaques. Then the plaques were observed by an optical microscope with the magnification of $400 \times^{[27]}$.

\section{MDA level measurement}

MDA level was detected by thiobarbituric acid method in brain tissue. Four rats were chosen randomly from any group, and their brains were extracted and homogenized in ice with $0.1 \mathrm{M}$ of phosphate buffer. The brains were then centrifuged at $300 \times \mathrm{g}$ at $4{ }^{\circ} \mathrm{C}$ for $10 \mathrm{~min}$, and supernatants were collected. Finally, thiobarbituric acid kit (Nalondi ${ }^{\text {TM}}$-Lipid Peroxidation Assay Kit-MDA, Navandsalamat Co., Iran) was used to determine the MDA level in the supernatant.

\section{SOD enzyme activity measurement}

SOD enzyme activity was assessed by colorimetric commercial kit (ZellBio GmbH, Ulm, Germany). SOD activity was determined as the amount of sample catalyzes the decomposition of $1 \mu \mathrm{mol}$ of superoxide radical into hydrogen peroxide and molecular oxygen in one minute. In this assessment, $65 \mu \mathrm{L}$ of phosphate buffered saline $(\mathrm{pH} 7.4)$ and $30 \mu \mathrm{L}$ of 3-(4,5dimethylthiazol- 2-yl)-2,5diphenyltetrazolium bromide (1.25 mM), along with $75 \mu \mathrm{L}$ of pyrogalum $(100 \mu \mathrm{M})$, were mixed with $10 \mu \mathrm{L}$ of homogenized hippocampus tissue and incubated at room temperature for $5 \mathrm{~min}$. Next, $0.75 \mu \mathrm{L}$ of DMSO was added to the mixture, and the light absorption was read by ELISA atthe wavelength of $420 \mathrm{~nm}^{[28]}$.

\section{IL-1 $\beta$ and TNF- $\alpha$ levels measurement}

To measure proinflammatory cytokines, four rats were chosen and their brains were extracted and homogenized in ice with $0.1 \mathrm{M}$ of phosphate buffer with protease inhibitor cocktail $(1.5 \mathrm{mM}$ of Pepstatin A, $104 \mathrm{mM}$ of 4-benzenesulfonyl fluoride hydrochloride, $80 \mu \mathrm{M}$ of aprotinin, $4 \mathrm{mM}$ of bestatin, $1.4 \mathrm{mM}$ of E-64, and $2 \mathrm{mM}$ of Leupeptin,) with a ratio of protease inhibitor to sample (1:100). The homogenized brain samples were then centrifuged at $300 \times \mathrm{g}$ at $4{ }^{\circ} \mathrm{C}$ for $20 \mathrm{~min}$, and supernatants were collected and used for IL- $1 \beta$ and TNF- $\alpha$ ELISA kits (R\&D Systems, USA).

\section{Statistical analysis}

GraphPad Prism 7.0 was used to analyze the data. All data were shown with mean \pm SEM. In behavioral study, two-way ANOVA, followed by post hoc Tukey's test was applied to compare the results of different days (escape latency). In other studies, oneway ANOVA was used to compare the results between groups. $p<0.05$ was considered statistically significant.

\section{Ethical statement}

The above-mentioned sampling/treatment protocols were approved by the Ethics Committee for the Care and Use of Laboratory Animals at the Tehran University of Medical Sciences, Tehran, Iran (ethical code: IR.TUMS.MEDICINE.REC.1397.376).

\section{RESULTS}

\section{Probiotics mixture improved A $\beta$-induced spatial learning, and memory impairment}

To assess spatial memory and learning, MWM was used. Escape latency to arrive to the hidden platform showed that from the first day until the fourth day of training phase, spatial memory improved in all groups. A $\beta$-treated group had longer time latency in comparison with the control and sham groups in MWM training phase $(p<0.001)$. Administration of probiotics promoted spatial memory and learning in comparison with $\mathrm{A} \beta$-treated group $(p<0.01)$. The probiotics-treated group had no difference with the positive control (rivastigmine $+\mathrm{A} \beta$-treated group), meaning that probiotics had a treatment effect similar to rivastigmine (Fig. 2A). In addition, during the probe test, time was measured in target quadrant that contained hidden platform previously. In A $\beta$-treated group, time in target quadrant diminished in comparison with the control and sham groups $(p<$ $0.01)$. These data indicated that rats treated with $\mathrm{A} \beta$ could not remember that in which quadrant the hidden platform was placed. However, probiotics administration improved their spatial memory, and there was no difference between the probiotics-treated group and the control and sham groups (Fig. 2B). The analysis of swimming speed indicated no significant difference between the groups. These data showed no disability of motor functions in all the groups (Fig. 2C). 

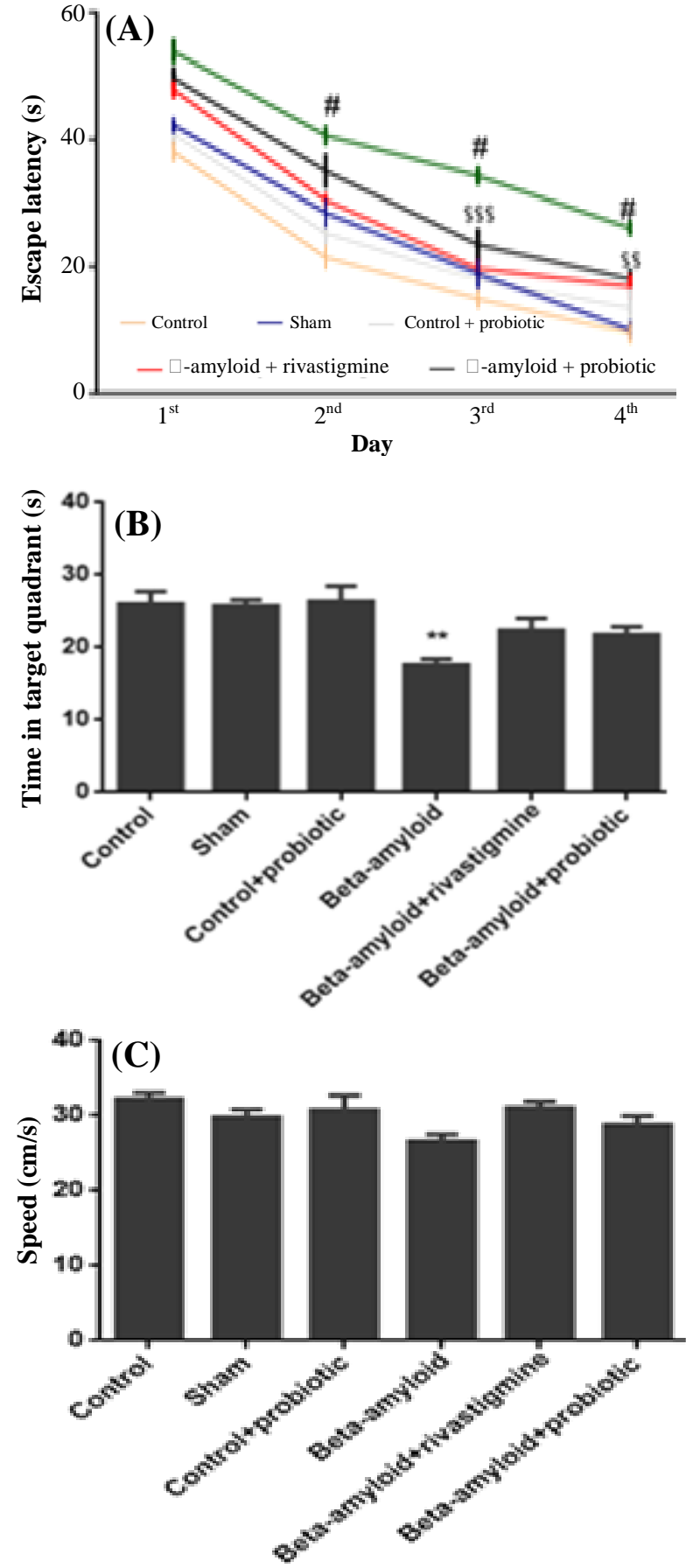

Fig. 2. Improvement of $A \beta$-induced spatial learning and memory impairment by probiotics mixture. (A) Analysis of escape latency (time to find hidden platform) showed a significant difference between A $\beta$-treated animals and control and sham group $\left({ }^{\#} p<0.001\right)$. In addition, escape latency data denoted significant difference between $\mathrm{A} \beta$ group and $\mathrm{A} \beta+$ probiotics group $\left({ }^{\$ \$} p<0.001\right.$ and $\left.{ }^{\$ \$} p<0.01\right)$. (B) Data from probe test revealed that $A \beta$-treated animals had significantly less time in the target quadrant in comparison with other groups $\left({ }^{* *} p\right.$ $<0.01$ ). (C) Swimming speed analysis showed no significant difference between the groups ( $\mathrm{n}=10$ rats per group). In 2B and $2 \mathrm{C}$, one-way ANOVA with post-hoc Tukey's test were used to analyze the data. Data were represented as mean \pm SEM.
Probiotics mixture diminished $A \beta$ deposition in hippocampus of $A \beta$-treated rats

To determine $A \beta$ deposition in hippocampus of rats, Congo red staining was used. Based on the Figure 3, $\mathrm{A} \beta$ injection in the right hippocampus (CA-1 region) could make $A \beta$ plaques in the brain of rats. Probiotics mixture in animals treated with $A \beta$ could inhibit making $A \beta$ deposition in hippocampus; therefore, in this group, $A \beta$ plaques were disappeared. In addition, the group that received rivastigmine (the positive control), $A \beta$ deposition diminished, but probiotics had a better effect on the clearance of $A \beta$ deposition in rats' brains.

Probiotics mixture reduced MDA level and augmented SOD activity in A $\beta$-treated group

In this study, to measure oxidative stress level, MDA was used (Fig. 4A). As expected, $\mathrm{A} \beta$ injection increased MDA level as an important oxidative marker in comparison with the sham group $(p<0.001)$. However, administration of probiotics mixture demonstrated a significant decrement in MDA level in comparison with A $\beta$-treated group $(p<0.001)$. Although rivastigmine could decrease MDA level in comparison with A $\beta$-treated group $(p<0.01)$, probiotics administration had more potent antioxidant activity versus rivastigmine $+A \beta$-treated group. SOD activity, as an antioxidant enzyme, was measured and increased versus sham group $(p<0.05)$. In addition, in rivastigmine $+\mathrm{A} \beta$-treated group, SOD activity increased in comparison with the sham group ( $p<$ 0.01 ) and more than $\mathrm{A} \beta$-treated group (Fig. 4B). Also, probiotics administration could augment SOD activity versus the sham group $(p<0.001)$, and probiotics had a positive effect even more than rivastigmine on increasing SOD activity.

\section{Probiotics mixture reduced inflammation markers} level (IL-1 $\beta$ and TNF- $\alpha$ ) in A $\beta$-treated group

$\mathrm{A} \beta$-treated rats significantly exhibited an elevation of IL-1 $\beta(p<0.01)$ and TNF- $\alpha(p<0.01)$ levels in hippocampal tissue supernatant compared to the sham group (Fig. 5). Probiotics mixture could also decrease IL-1 $\beta(p<0.01)$ and TNF- $\alpha(p<0.01)$ levels significantly in comparison with $A \beta$-treated rats. As data showed, probiotics mixture attenuated inflammation markers in hippocampus tissue in comparison with $A \beta$ intrahippocampal microinjection group.

\section{DISCUSSION}

The present study revealed that probiotics play an effective role in the improvement of memory impairment in the $\mathrm{AD}$ model of rats, as well as of 

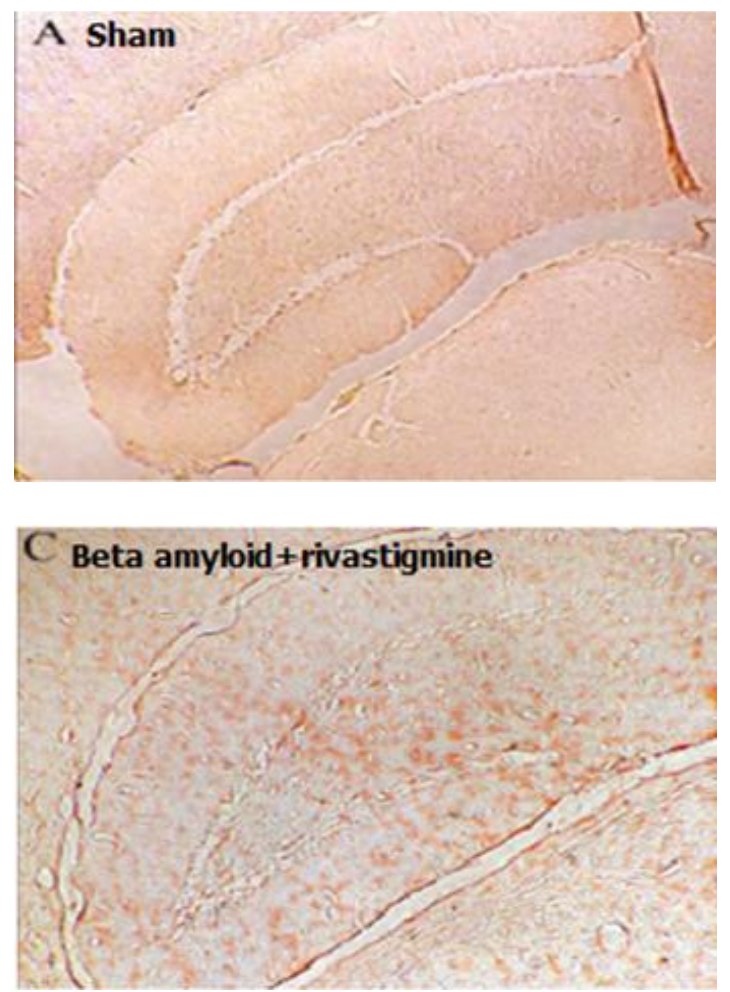
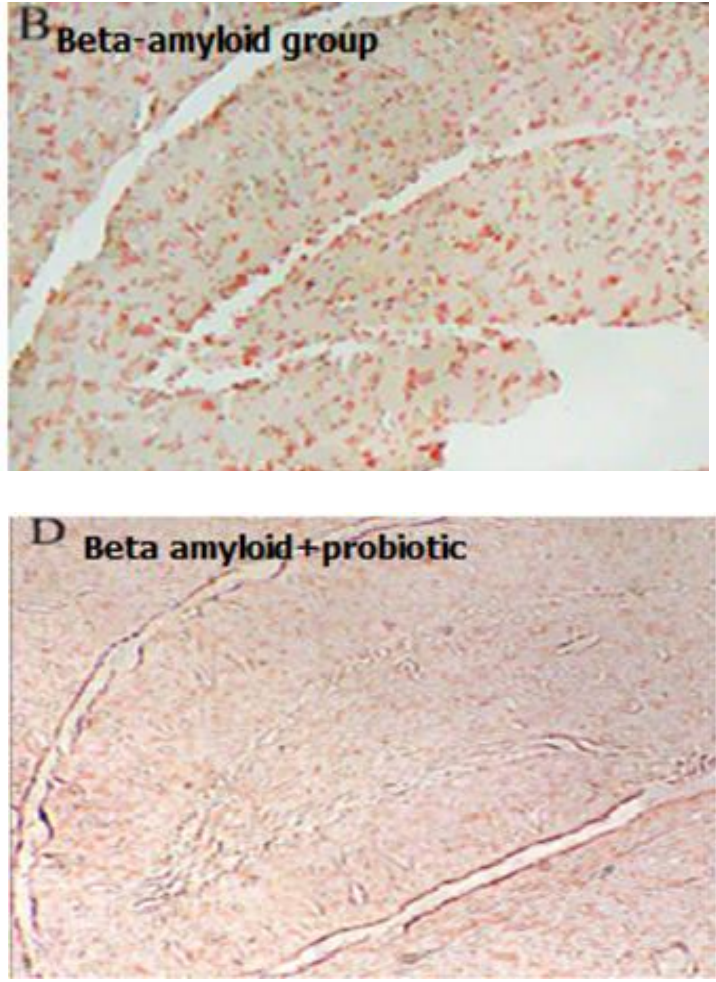

Fig. 3. Reduction of $A \beta$ deposition in the hippocampus of $A \beta$-treated rats by Probiotics mixture. CA-1 region neuronal sections. Administration of $A \beta$ intrahippocampal caused $A \beta$ deposition in hippocampus in comparison with sham group. Ten weeks administration of probiotics had a positive effect on $A \beta$ plaques inhibition even better than $A \beta+$ rivastigmine group (positive control).

memory and learning in the MWM test. In our histological study, probiotics administration decreased $\mathrm{A} \beta$ aggregation in hippocampus in an $\mathrm{AD}$ model. In addition, probiotics attenuated neuroinflammation by reducing inflammation and oxidative stress markers in animals with $\mathrm{A} \beta$ intrahippocampal microinjection. Evidence has indicated that oxidative stress acts as a trigger for the deposition and accumulation of $A \beta$ in $\mathrm{AD}$ through the production of reactive oxygen species $^{[29-31]}$. Our data showed that the administration of probiotics mixture for 10 weeks improved delay in escape latency in the AD model of rats in MWM test. This finding suggested a significant improvement in spatial memory consolidation. Our finding also showed that probiotics reduced augmented MDA level, as an oxidative marker, and IL- $1 \beta$ and TNF- $\alpha$ levels, as important inflammation markers.

SODs convert superoxide to hydrogen peroxide, which is removed by glutathione peroxidase or catalase $^{[32,33]}$. In the present study, probiotics increased the SOD enzyme level, indicating that probiotics have an antioxidative effect on the $\mathrm{AD}$ model. It has also been shown that probiotics play the same role in GIT and reduce intestinal oxidative stress and neuroinflammatory cytokines in several experimental models $^{[34-36]}$. There are several theories on the relationship between alternation in microbiota and neuroinflammatory disorders. Gut microbiota is required for normal immune system maturation, which can influence the adaptive and innate immune systems in completely different ways ${ }^{[37-39]}$.

Studies on MS, as a neuroinflammation disorder, have shown that probiotics can be helpful in reducing inflammatory cytokines in MS patients. Probiotics supplement decreased IL-6 levels and increased IL-10 concentration (as an anti-inflammatory cytokine) in the serum of MS patients ${ }^{[40]}$. Probiotics treatment improved clinical symptoms by creating a balance in inflammatory and anti-inflammatory responses in MS patients ${ }^{[9,40]}$. In fact, probiotics mixture can be useful in the treatment of neurodegenerative and neuroinflammatory diseases through their immunemodulatory effects ${ }^{[41,42]}$. There are many relationships between gut and brain at molecular levels. The gutbrain axis is a dynamic bidirectional neuroendocrine system describing the connections between the GIT and the nervous system ${ }^{[43,44]}$. There are many common regulatory factors between the enteric nervous system and the CNS. Studies have revealed that gut microbiota dysbiosis is related to many neuroinflammatory and neurodegenerative diseases ${ }^{[44]}$. Microbiota-associated molecular patterns can activate the host innate immune 

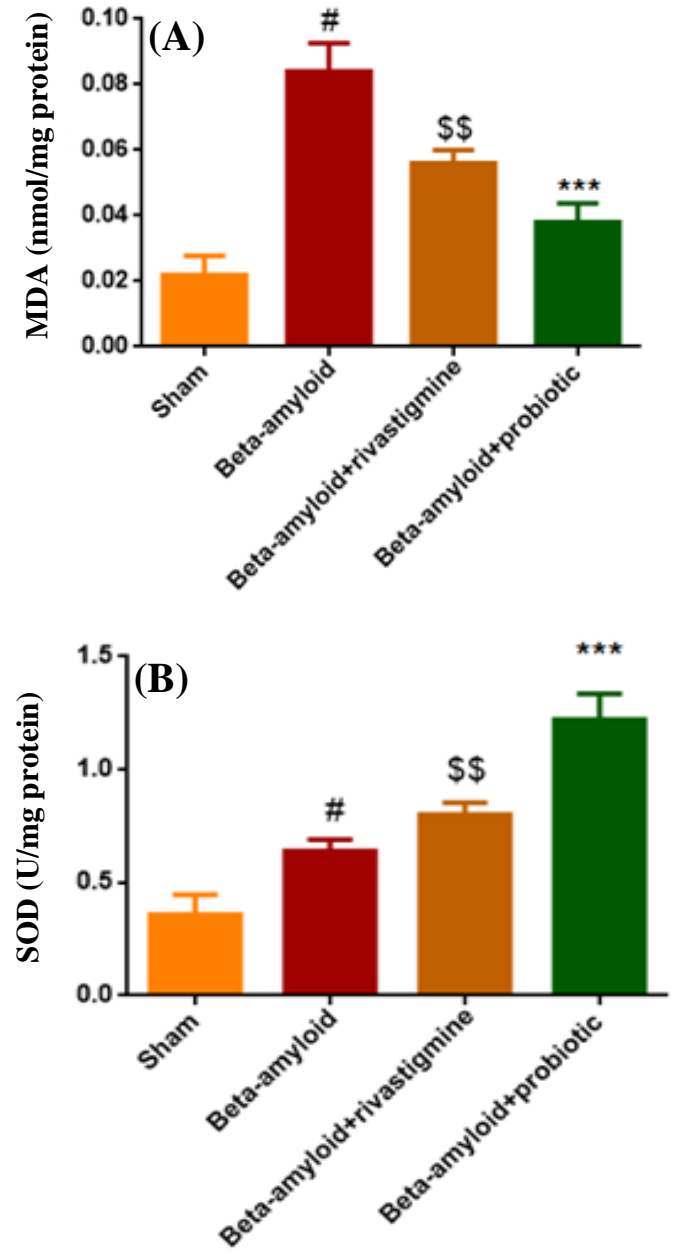

Fig. 4. Reduction of MDA level and augmentation of SOD activity in $A \beta$-treated group by probiotics mixture. (A) MDA level increased significantly in $A \beta$ group in comparison with the sham group $\left({ }^{\#} p<0.001\right)$; rivastigmine and probiotics reduced MDA activity versus $A \beta$ group $\left({ }^{\$} p<0.01\right.$ and $\left.{ }^{* * * *} p<0.001\right)$. (B) SOD activity increased significantly in all groups in comparison with sham group $\left({ }^{\#} p<0.01,{ }^{\$} p<0.01,{ }^{* * *} p<0.001\right)$. Data were represented as mean \pm SEM $(n=4)$. One-way ANOVA was used as statistical analysis with post-hoc Tukey's test. "shows the difference between $A \beta$ group vs. sham group; \$shows the difference between $A \beta$ group vs. $A \beta+$ rivastigmine; "shows the difference between $A \beta$ group vs. $A \beta+$ probiotic.

system via pattern-recognition receptors such as tolllike receptors and nucleotide-binding domain and leucine-rich repeat containing receptors (NOD-like receptors) that are present in intestinal epithelial and myeloid cells ${ }^{[42]}$. Thus, the activation of toll-like receptors and NOD-like receptors could be implicated in the mechanisms by which gut microbiota trigger many neuroimmune disorders ${ }^{[45]}$. The beneficial effects of probiotics therapy is likely the improvement of the intestinal barrier function, which leads to the prevention of a continuous stimulation of the host innate immune system by the gut microbiome and inhibition of releasing proinflammatory factors in blood flow, in order to advance neuroinflammation in $\mathrm{CNS}^{[46]}$. In general, there is a loss of gut microbial diversity in the aging gut. In a few studies, there were significant variations in the composition of the gut microbiota in aging patients suffering from neurodegenerative diseases ${ }^{[47,48]}$. Various probiotics produce different neuroactive molecules that directly or indirectly impact signaling in the CNS. There are many interlocking hormonal and biochemical pathways relating GIT health to the brain and creating a strong therapeutic potential for probiotics use against neurodegeneration ${ }^{[42]}$. In previous studies, probiotics mixture of Lactobacillus reuteri, Lactobacillus rhamnosus, and Bifidobacterium infantis succeeded in the treatment of many inflammatory bowel diseases ${ }^{[49-51]}$. Our study
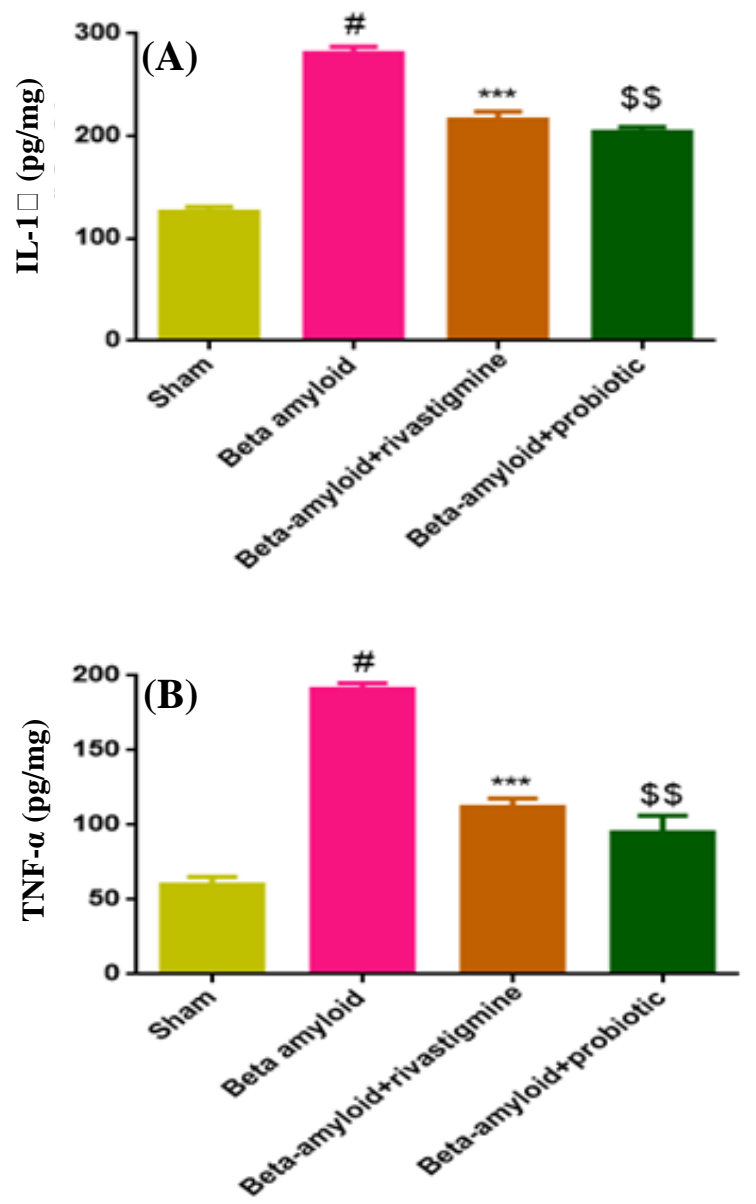

Fig. 5. Reduction of inflammation makers level (IL-1 $\beta$ and TNF- $\alpha$ ) in A $\beta$-treated group by probiotics mixture. Data were represented as mean \pm SEM $(n=4)$. In A $\beta$-treated group, IL-1 $\beta$ (A) and TNF- $\alpha$ (B) increased versus sham group $\left({ }^{\#} p<0.01\right)$. Treatment with probiotics mixture in $\mathrm{A} \beta$-treated rats decreased IL- $1 \beta$ and TNF- $\alpha$ levels like rivastigmine group $\left({ }^{* * *} p<0.001\right.$, $\$ \$ p<0.001)$. One-way ANOVA was used as statistical analysis with post-hoc Tukey's test. ${ }^{\#}$ shows the difference between $A \beta$ group vs. sham group; ${ }^{*}$ shows the difference between $A \beta$ group vs. $A \beta+$ rivastigmine; ${ }^{\$}$ shows the difference between $A \beta$ group vs $A \beta+$ probiotics. 
also revealed that probiotics mixture of the three mentioned bacteria can slow down the progression of oxidative stress and neuroinflammation in $\mathrm{AD}$ model of rats.

The findings of the present study demonstrated that the 10 -week consumption of probiotics in the AD model of rats had favorable effects on memory deficit, oxidative stress markers, and proinflammatory cytokines. This study clarified that probiotics can serve as an effective treatment in many neurodegenerative diseases along with other effective drugs in AD patients.

\section{ACKNOWLEDGEMENTS}

This study was financially supported by a research grant (no. 97-01-139-38065) from Electrophysiology Research Center, Neuroscience Institute, Tehran University of Medical Sciences, Tehran, Iran.

CONFLICT OF INTEREST. None declared.

\section{REFERENCES}

1. Bertram L, Lill CM, Tanzi RE. The genetics of Alzheimer disease: back to the future. Neuron 2010; 68(2): 270-281.

2. Citron M. Alzheimer's disease: strategies for disease modification. Nature reviews drug discovery 2010; 9(5): 387-398.

3. Swomley AM, Förster S, Keeney JT, Triplett J, Zhang Z, Sultana R, Butterfield DA. Abeta, oxidative stress in Alzheimer disease: evidence based on proteomics studies. Biochimica et biophysica acta 2014; 1842(8): 1248-1257.

4. Mehrabadi S, Motevaseli E, Sadr SS, Moradbeygi K. Hypoxic-conditioned medium from adipose tissue mesenchymal stem cells improved neuroinflammation through alternation of toll like receptor (TLR) 2 and TLR4 expression in model of Alzheimer's disease rats. Behavioural brain research 2020; 379: 112362.

5. Bubici C, Papa S, Dean K, Franzoso G. Mutual crosstalk between reactive oxygen species and nuclear factorkappa B: molecular basis and biological significance. Oncogene 2006; 25(51): 6731-6748.

6. Chapple I. Reactive oxygen species and antioxidants in inflammatory diseases. Journal of clinical periodontology 1997; 24(5): 287-296.

7. Hill JM, Clement C, Pogue AI, Bhattacharjee S, Zhao Y, Lukiw WJ. Pathogenic microbes, the microbiome, and Alzheimer's disease (AD). Frontiers in aging neuroscience 2014; 6: 127.

8. Ticinesi A, Tana C, Nouvenne A, Prati B, Lauretani F, Meschi T. Gut microbiota, cognitive frailty and dementia in older individuals: a systematic review.
Clinical interventions in aging 2018; 13: 1497-1511.

9. Mehrabadi S. Interaction between gut microbiota dysbiosis and multiple sclerosis. International journal of medical investigation 2019; 8(3): 21-28.

10. Mulak A, Bonaz B. Brain-gut-microbiota axis in Parkinson's disease. World journal of gastroenterology 2015; 21(37): 10609-10620.

11. Borre YE, Moloney RD, Clarke G, Dinan TG, Cryan JF. The Impact of Microbiota on Brain and Behavior: Mechanisms \& Therapeutic Potential. In: Lyte M., Cryan J, editors. Microbial Endocrinology: The Microbiota-Gut-Brain Axis in Health and Disease. Advances in Experimental Medicine and Biology. New York: Springer; 2014. P. 373-403.

12. Hsiao EY, McBride SW, Hsien S, Sharon G, Hyde ER, McCue T, Codelli JA, Chow J, Reisman SE, Petrosino JF, Patterson PH, Mazmanian SK. Microbiota modulate behavioral and physiological abnormalities associated with neurodevelopmental disorders. Cell 2013; 155(7): 1451-1463.

13. Nimgampalle M, Kuna Y. Anti-Alzheimer properties of probiotic, Lactobacillus plantarum MTCC 1325 in Alzheimer's disease induced albino rats. Journal of clinical and diagnostic research 2017; 11(8): KC01KC05.

14. Cowan CSM, Hoban AE, Ventura- Silva AP, Dinan TG, Clarke G, Cryan JF. Gutsy moves: the amygdala as a critical node in microbiota to brain signaling. Bioessays 2018; 40(1): doi: 10.1002/bies.

15. Bravo JA, Forsythe P, Chew MV, Escaravage E, Savignac HM, Dinan TG, Bienenstock J, Cryan JF. Ingestion of Lactobacillus strain regulates emotional behavior and central GABA receptor expression in a mouse via the vagus nerve. Proceedings of the national academy of sciences USA 2011; 108(38): 16050-16055.

16. Hestad KA, Engedal K, Whist JE, Farup PG. The relationships among tryptophan, kynurenine, indoleamine 2,3-dioxygenase, depression, and neuropsychological performance. Frontiers in psychology 2017; 8(1561). doi: 10.3389/fpsyg.2017. 01561.

17. Köhler CA, Maes M, Slyepchenko A, Berk M, Solmi M, Lanctôt KL, Carvalho AF. The gut-brain axis, including the microbiome, leaky gut and bacterial translocation: mechanisms and pathophysiological role in Alzheimer's disease. Current pharmaceutical design 2016; 22(40): 6152-6166.

18. Luckow T, Sheehan V, Fitzgerald G, Delahunty C. Exposure, health information and flavour-masking strategies for improving the sensory quality of probiotic juice. Appetite 47(3): 315-323.

19. Lukiw WJ, Bazan NG. Survival signalling in Alzheimer's disease. Biochemical society transactions 2006; 34(6): 1277-1282.

20. Bagyinszky E, Giau VV, Shim K, Suk K, An SSA, Kim $\mathrm{S}$. Role of inflammatory molecules in the Alzheimer's disease progression and diagnosis. Journal of the neurological sciences 2017; 376: 242-254.

21. Quigley EM. Prebiotics and probiotics; modifying and mining the microbiota. Pharmacological research 2010; 
61(3): 213-218

22. Zhang $X$, Zhao Y, Zhang M, Pang X, Xu J, Kang C, Li M, Zhang C, Zhang Z, Zhang Y, Li X, Ning G, Zhao L. Structural changes of gut microbiota during berberinemediated prevention of obesity and insulin resistance in high-fat diet-fed rats. PloS one 2012; 7(8): e42529.

23. Mallikarjuna N, Praveen K, Yellamma K. Role of Lactobacillus plantarum MTCC1325 in membranebound transport ATPases system in Alzheimer's disease-induced rat brain. Bioimpacts 2016; 6(4): 203209.

24. Mehrabadi S, Karimiyan SM. Morphine Tolerance Effects on Neurotransmitters and Related Receptors: Definition, Overview and Update. Journal of pharmaceutical research international 2018; 23(6): 111.

25. Paxinos G, Watson C. The Rat Brain in Stereotaxic Coordinates: Hard Cover Edition: Elsevier; 2006.

26. Vorhees CV, Williams MT. Morris water maze: procedures for assessing spatial and related forms of learning and memory. Nature protocols 2006; 1(2): 848858.

27. Frank S, Copanaki E, Burbach GJ, Müller UC, Deller T. Differential regulation of toll-like receptor mRNAs in amyloid plaque-associated brain tissue of aged APP23 transgenic mice. Neuroscience letters 2009; 453(1): 4144.

28. Przedborski S, Jackson- Lewis V, Kostic V, Carlson E, Epstein C, Cadet J. Superoxide dismutase, catalase, and glutathione peroxidase activities in copper/zincsuperoxide dismutase transgenic mice. Journal of neurochemistry 1992; 58(5): 1760-1767.

29. Qin L, Liu Y, Cooper C, Liu B, Wilson B, Hong JS. Microglia enhance $\beta$ - amyloid peptide- induced toxicity in cortical and mesencephalic neurons by producing reactive oxygen species. Journal of neurochemistry 2002; 83(4): 973-983.

30. Zuo L, Hemmelgarn BT, Chuang CC, Best TM. The role of oxidative stress-induced epigenetic alterations in amyloid- $\beta$ production in Alzheimer's disease. Oxidative medicine and cellular longevity 2015; 2015: 604658.

31. Mehrabadi S, Sadr SS, Hoseini M. Stem cell conditioned medium as a novel treatment for neuroinflamation diseases. International journal of medical investigation 2019; 8(3): 1-12.

32. Ighodaro O, Akinloye O. First line defence antioxidantssuperoxide dismutase (SOD), catalase (CAT) and glutathione peroxidase (GPX): Their fundamental role in the entire antioxidant defence grid. Alexandria journal of medicine 2018; 54(4): 287-293.

33. Afonso V, Champy R, Mitrovic D, Collin P, Lomri A. Reactive oxygen species and superoxide dismutases: role in joint diseases. Joint bone spine 2007; 74(4): 324329.

34. Berry D, Kaplan J, Rahman S. Probiotic compositions containing clostridiales for inhibiting inflammation. Google Patents; 2017.

35. Gao C, Major A, Rendon D, Lugo M, Jackson V, Shi Z, Mori-Akiyama Y, Versalovic J. Histamine H2 receptormediated suppression of intestinal inflammation by probiotic Lactobacillus reuteri. mBio 2015; 6(6): e01358-15.

36. Koon HW, Su B, Xu C, Mussatto CC, Tran DH-N, Lee EC, Ortiz C, Wang J, Lee JE, Ho S, Chen X, Kelly CP, Pothoulakis C. Probiotic Saccharomyces boulardii CNCM I-745 prevents outbreak-associated Clostridium difficile-associated cecal inflammation in hamsters. American journal of physiology-gastrointestinal and liver physiology 2016; 311(4): G610-G23.

37. Rooks MG, Garrett WS. Gut microbiota, metabolites and host immunity. Nature reviews immunology 2016; 16(6): 341-352.

38. Thaiss CA, Zmora N, Levy M, Elinav E. The microbiome and innate immunity. Nature 2016; 535(7610): 65-74.

39. Maslowski KM, Mackay CR. Diet, gut microbiota and immune responses. Nature immunology 2011; 12(1): 59.

40. Calvo-Barreiro L, Eixarch H, Montalban X, Espejo C. Combined therapies to treat complex diseases: The role of the gut microbiota in multiple sclerosis. Autoimmunity reviews 2018; 17(2): 165-174.

41. Secher T, Kassem S, Benamar M, Bernard I, Boury M, Barreau F, Oswald E, Saoudi A. Oral administration of the probiotic strain Escherichia coli Nissle 1917 reduces susceptibility to neuroinflammation and repairs experimental autoimmune encephalomyelitis-induced intestinal barrier dysfunction. Frontiers in immunology 2017; 8: 1096.

42. Westfall S, Lomis N, Kahouli I, Dia SY, Singh SP, Prakash S. Microbiome, probiotics and neurodegenerative diseases: deciphering the gut brain axis. Cellular and molecular life sciences 2017; 74(20): 3769-87.

43. Foster JA, McVey Neufeld KA. Gut-brain axis: how the microbiome influences anxiety and depression. Trends in neurosciences 2013; 36(5): 305-312.

44. Fung TC, Olson CA, Hsiao EY. Interactions between the microbiota, immune and nervous systems in health and disease. Nature neuroscience 2017; 20(2): 14-155.

45. Caputi V, Giron M. Microbiome-gut-brain axis and tolllike receptors in Parkinson's disease. International journal of molecular sciences 2018; 19(6): doi: 10.3390/ijms 19061689.

46. Ohland CL, MacNaughton WK. Probiotic bacteria and intestinal epithelial barrier function. American journal of physiology-gastrointestinal and liver physiology 2010; 298(6): G807-G819.

47. Claesson MJ, Jeffery IB, Conde S, Power SE, O'Connor EM, Cusack S, Harris HM, Coakley M, Lakshminarayanan B, O'Sullivan O, Fitzgerald GF, Deane J, O'Connor M, Harnedy N, O'Connor K, O'Mahony D, van Sinderen D, Wallace M, Brennan L, Stanton C, Marchesi JR, Fitzgerald AP, Shanahan F, Hill C, Ross RP, O'Toole PW. Gut microbiota composition correlates with diet and health in the elderly. Nature 2012; 488(7410): 178-184.

48. Nicholson JK, Holmes E, Kinross J, Burcelin R, Gibson G, Jia W, Pettersson S. Host-gut microbiota metabolic interactions. Science 2012; 336(6086): 1262-1267. 
49. van der Kleij H, O'Mahony C, Shanahan F, O'Mahony L, Bienenstock J. Protective effects of Lactobacillus reuteri and Bfidobacterium infantis in murine models for colitis do not involve the vagus nerve. American journal of physiology-regulatory, integrative and comparative physiology 2008; 295(4): R1131-R1137.

50. Ewaschuk JB, Diaz H, Meddings L, Diederichs B, Dmytrash A, Backer J, Looijer-van Langen M, Madsen KL. Secreted bioactive factors from Bifidobacterium infantis enhance epithelial cell barrier function.
American journal of physiology-gastrointestinal and liver physiology 2008; 295(5): G1025-G1034.

51. Rodes L, Khan A, Paul A, Coussa-Charley M, Marinescu D, Tomaro-Duchesneau C, Shao W, Kahouli I, Prakash S. Effect of probiotics Lactobacillus and Bifidobacterium on gut-derived lipopolysaccharides and inflammatory cytokines: an in vitro study using a human colonic microbiota model. Journal of microbiology and biotechnology 2013; 23(4): 518-526. 